Pecvnia, 7 (2008), pp. 257-284

\title{
El proceso de reforma económica de China y su adhesión a la OMC
}

Recibido: Octubre 2008 Aceptado: Mayo 2009
Ana I. Salvador Chamorro

ana.salvador@unileon.es Universidad de León

Fac. de Ciencias Económicas y Empresariales Campus de Vegazana, $\mathrm{s} / \mathrm{n}$

24071 León (España)
Como es sabido, China inició hace tres décadas un proceso de reformas que ha transformado por completo su economía. El objetivo de este trabajo es exponer de forma ordenada las medidas introducidas hasta el momento actual haciendo especial hincapié en los cambios más recientes. Para ello dividiremos el proceso reformista en tres etapas: las primeras reformas (desde 1978 hasta mediados de los noventa), las reformas de los noventa $y$, por último, las aplicadas a partir de la adhesión de China a la Organización Mundial de Comercio (OMC).

Palabras clave: China, reforma económica, transición, OMC, relaciones de inversión, relaciones comerciales.
As is well known, China began a process of reforms three decades ago which has totally transformed its economy. The aim of this study is to orderly put forward the measures taken till the present moment, emphasizing the most recent changes. For that reason we will distinguish three stages in the reform process: the early reforms (from 1978 till the middle of the nineties), the nineties reforms and, finally, the measures taken after the accession of China to the World Trade Organization (WTO).

Key words: China, economic reform, transition, WTO, investment relations, commercial relations. 


\section{INTRODUCCIÓN}

A finales del año 1978 comenzó en China un proceso de reforma y apertura, que constituyó uno de los acontecimientos económicos de mayor relevancia del siglo XX, tanto dentro del país como fuera de él. La meta de este proceso era la construcción de una economía de mercado socialista con miras a modernizar el país más poblado del mundo, es decir, materializar un socialismo con peculiaridades chinas. China se embarcó en un proceso de reforma de su economía que, sin haberlo planificado de forma expresa, en la práctica ha ido introduciendo paulatinamente los mecanismos propios de la economía de mercado, presentando, por la estrategia desarrollada, un caso único en el mundo.

El objetivo de este trabajo es exponer de forma ordenada las medidas de reforma introducidas por China hasta el momento actual haciendo especial hincapié en los cambios más recientes. Para ello dividiremos el proceso reformista en tres etapas: las primeras reformas (desde 1978 hasta mediados de los noventa), las reformas de los noventa y, por último, las aplicadas a partir de la adhesión de China a la Organización Mundial de Comercio (OMC).

\section{LAS PRIMERAS REFORMAS ECONÓMICAS}

La reforma que inició Deng Xiaoping en 1978 se ha distinguido de las anteriores en que por primera vez se antepusieron los objetivos económicos a las cuestiones políticas. De este modo, el gobierno apostó por el crecimiento económico como motor de la reforma sin plantearse un proceso de liberalización en lo político, es decir, sin abandonar el régimen comunista.

Ésta es una de las muchas diferencias que existen entre la reforma china y la llevada a cabo por otras economías socialistas en su transición hacia el mercado. En contraposición a la opción ortodoxa - conocida como big bang o transición rápida-, China optó por una reforma caracterizada por el gradualismo -tanto geográfico como sectorial-y por la experimentación ${ }^{1}$. Tal y como lo expresa Nolan (1994), la transición 
gradual consistiría en "pisar las piedras para cruzar el río", en lugar de tratar de atravesarlo de un solo salto.

En la práctica las medidas reformistas de esta primera etapa se concretaron en dos direcciones: las Cuatro Modernizaciones y la política de puertas abiertas. Se denominó las Cuatro Modernizaciones a un conjunto de medidas liberalizadoras en el campo de la agricultura, la industria, el ejército, y la ciencia y tecnología. De ellas, las que más nos interesan desde el punto de vista económico son la reforma agraria y la industrial.

Como resalta Perkins (1994), la secuenciación de la reforma fue consecuencia de la percepción del gobierno sobre la complejidad de llevar a cabo las medidas necesarias; por ello, el cambio se inició en los sectores "fáciles de reformar" (la agricultura y el comercio exterior) y, más adelante, se acometió una tarea más difícil: la de reformar el sector industrial $y$, en especial, las grandes empresas de propiedad estatal.

A grandes rasgos, el objetivo de esta primera etapa reformista fue crear progresivamente espacios de actividad económica al margen del sistema de planificación central (Naughton 2007).

El sector agrícola fue el punto de partida de la reforma, dado que fue considerado, por diversas cuestiones, el sector prioritario por el gobierno de China ${ }^{2}$. La reforma agraria comenzó con la descolectivización del campo y la supresión de las comunas, creadas durante el Gran Salto Adelante. En su lugar, se volvió a la explotación familiar, pero no se repartió la propiedad de la tierra; es decir, formalmente los derechos de propiedad seguían siendo del Estado y éste tenía la potestad de alquilar las tierras a los campesinos. Además se instauró un "sistema de responsabilidad familiar", que autorizaba a los hogares agrícolas a tomar decisiones sobre un buen número de cuestiones relacionadas con aspectos como el tipo de cultivo, la adquisición de inputs, etc. De acuerdo con este sistema, las relaciones del campesinado con el Estado comenzaron a formalizarse a través de contratos, en los cuales se plasmaba el compromiso del campesino a vender al Estado -a un precio especial, administrativamente fijado- una cantidad previamente pactada de su cosecha. El resto de la misma podía ser vendida en los mercados libres a los precios fijados por la oferta y la demanda, muy superiores a los pagados por el Estado. Este sistema cuasi-privado de precios duales

2 Véase Huang, Otsuka y Rozelle (2008). 
permitió la introducción paulatina de mercados libres, y con ello, de precios determinados por el mercado para muchos productos agrícolas (Bustelo y Fernández Lommen 1996).

La aplicación de estas medidas dio muy buenos resultados, mejoró el bienestar rural y tuvo efectos indirectos muy positivos sobre otros sectores; además, el éxito de la reforma agraria tuvo un papel trascendental como soporte político para continuar el programa de reformas.

De este modo, siguiendo el gradualismo sectorial de la reforma, a mediados de los ochenta -hacia 1984- se puso en marcha la reforma industrial ${ }^{3}$. Hasta ese momento el sector estaba constituido íntegramente por empresas de propiedad estatal, que funcionaban como agentes pasivos del sistema de planificación central, de manera que cumplían las instrucciones del gobierno sobre todas las cuestiones relativas a su actividad productiva. Los beneficios se transferían íntegramente al Estado, que decidía el destino de los mismos ${ }^{4}$. Esta rigidez, tan característica de estos sistemas, ocasionaba graves problemas en el sector, por lo que el objetivo primordial de esta etapa reformista fue intentar eliminarla a través de la aplicación de un proceso desregulador de la industria (Fanjul 1994).

Este proceso persiguió varios subobjetivos, como reducir la participación de Estado en la actividad empresarial, conceder una mayor autonomía de decisión a las empresas o introducir gradualmente los mecanismos de mercado. En esta primera reforma industrial las autoridades evitaron la privatización de la industria, aplicando en su lugar otras políticas para cambiar el comportamiento de los agentes y el sistema de incentivos que afectaba a las empresas industriales (Singh 1996).

Para conseguir estas metas la primera medida importante fue la de permitir (para posteriormente incentivar) la creación de empresas no estatales, lo que dio lugar a la aparición de capital extranjero y privado en las empresas - con distintas formas legales- cuyas características más

3 Con anterioridad se habían aplicado en el sector algunas reformas, pero éstas fueron de carácter parcial y experimental.

$4 \quad$ Bustelo y Fernández Lommen (1996a) señalan que solamente se reinvertía en el sector empresarial una mínima parte de los beneficios que generaba, de tal modo que, con el paso de los años, las plantas y la maquinaria quedaron muy atrasadas. 
importantes se desarrollarán en el apartado dedicado a las formas de inversión en China.

En segundo lugar, se introdujeron en las empresas estatales sistemas destinados a aumentar la responsabilidad de sus gerentes. En 1987 se introdujo el "sistema de responsabilidad por contratos", similar al agrícola, que permitía a las empresas disponer libremente de los beneficios que superaran un determinado nivel contractualmente determinado; es decir, según su criterio podían utilizarlo para reinvertirlo en la empresa, en otras empresas, para dar gratificaciones o primas a los trabajadores con el fin de incentivarlos, etc. Además se empezó a vincular los salarios de los gerentes a los resultados de las empresas ${ }^{5}$.

El siguiente paso fue la adopción de un sistema dual de precios, similar al agrícola, lo que permitió introducir progresivamente los precios libres en un sector que hasta entonces había estado muy intervenido. No obstante, esto tuvo el efecto colateral negativo de fomentar coyunturalmente la corrupción, ya que era posible lucrarse adquiriendo productos a precios oficiales para venderlos posteriormente en los canales privados a precios mucho más altos. Por este motivo, con el paso de los años el sistema dual se abandonó y se volvió a un sistema único de precios administrados, aunque, eso sí, estos precios se elevaron gradualmente para acercarse a los que surgirían del libre juego del mercado ${ }^{6}$.

Una de las características más destacables de la reforma industrial fue el crecimiento de las empresas rurales municipales (township and village enterprises, TVE) ${ }^{7}$, cuya importancia y contribución al éxito de la reforma industrial china y a su transición hacia el mercado es resaltada de forma generalizada.

Al igual que sucedió en el caso de la reforma agrícola, los resultados obtenidos en materia industrial fueron muy satisfactorios. La información empírica sobre el comportamiento empresarial, y sobre sus resultados, indica que los chinos también han tenido éxito en esta tarea. Por

\footnotetext{
5 Para un análisis de la reforma del sector industrial en China véase Jefferson y Rawski (1994).

6 El sistema dual desapareció definitivamente -como veremos- al ratificarse el acuerdo de adhesión de China a la Organización Mundial de Comercio a finales de 2001, dado que éste era uno de los compromisos asumidos por China en el mismo.

Son pequeñas empresas que operan normalmente a pequeña escala y que exhiben toda una variedad de regímenes de propiedad, siendo predominante la propiedad colectiva por aldeas y pueblos, y que operan en condiciones muy próximas al mercado.
} 
ejemplo, Groves et al. (1994) demuestran que la autonomía de las empresas se incrementó y que los gerentes reaccionaron positivamente, es decir, en la dirección de aumentar la eficiencia de las empresas. Asimismo, la introducción de incentivos a los trabajadores, además de incrementar sus rentas, tuvo efectos muy positivos sobre la productividad. No obstante, y como veremos más adelante, las reformas prosiguieron en la década siguiente.

Por otro lado, para financiar todo este proceso de reformas el gobierno chino optó por un cambio de procedimiento. Si históricamente la agricultura había aportado los recursos necesarios para el desarrollo del país, a principios de los ochenta este papel se le otorgó al sector exterior ${ }^{8}$. China abandonó su tradicional autarquía y comenzó un proceso de apertura al exterior -en el ámbito comercial y financiero- denominado política de puertas abiertas, cuyos objetivos principales fueron:

- Atraer capital y tecnología foráneos, para financiar el proceso y para modernizar el sector industrial.

- Fomentar las exportaciones de manufacturas, y con ello impulsar la entrada de divisas necesarias para financiar las importaciones y la deuda externa.

Así, en 1980 se inició la apertura con la creación de las zonas económicas especiales (ZEE) que se concibieron como áreas geográficas, dentro del territorio del país, donde el gobierno permitía una legislación económica más abierta que en el resto; además el gobierno incentivaba en ellas una serie de actividades productivas, habitualmente orientadas a la exportación, sin que esto fuese generalmente aplicable al resto del país. Con su implantación el gobierno pretendía, por un lado, atraer inversión extranjera directa (IDE), y, por otro "experimentar" o "ensayar" en ellas la aplicación de medidas económicas orientadas al mercado y evaluar sus efectos antes de implantarlas en todo el país.

Las empresas -extranjeras y chinas- asentadas en esas zonas operaban con gran libertad y recibían incentivos de distinta índole, como exenciones fiscales, mayor libertad para comerciar con el exterior,

8 En palabras de Fanjul (1996: 86), "China es consciente de que en el mundo exterior se hallan muchos elementos que son imprescindibles para su crecimiento económico: tecnología, capitales, mercados, métodos de gestión". 
facilidades burocráticas, etc., que originaron una sorprendente expansión en la actividad económica de las ZEE así como grandes flujos de capital extranjero y de transacciones comerciales con el exterior, sobre todo exportaciones. Como consecuencia, se fueron creando cada vez más zonas de similares características por todo el país.

Con todo, Ge (1999) destaca el papel de las ZEE como "laboratorios", dado que la evaluación de las políticas aplicadas en ellas ha legitimado a las autoridades para extenderlas a toda la economía. En su opinión, el establecimiento de las ZEE ha sido el paso más crucial de China en la reforma.

\section{LAS REFORMAS DE LOS NOVENTA}

A medida que se iban aplicando las medidas reformistas analizadas en el apartado anterior iba surgiendo la necesidad de nuevas reformas en otros ámbitos. Además, el éxito del programa reformista de Deng Xiaoping hizo que sus sucesores continuasen el proceso. En este contexto, en la década de los noventa se produjo un giro importante en la estrategia de transición, pasando de las reformas escalonadas y cautelosas de los ochenta a un programa de liberalización mucho más profundo a partir de mediados de los noventa. Ese giro se realizó con una relativa facilidad $-y$ con un notable éxito-, lo que, como señala Naughton (2004), constituye uno de los rasgos más llamativos de la transición hacia el mercado de China.

En efecto, los resultados de las reformas llevadas a cabo hacían de China una economía cada vez más capitalista, lo que a su vez hacía necesario cambios normativos e institucionales para afrontar ese nuevo contexto. De este modo las medidas reformistas de esta etapa (que duran hasta hoy) se han centrado en mejorar el entorno legal y regulatorio y en crear nuevas reglas acordes con su nueva economía. Las medidas más importantes se han llevado a cabo en el sistema fiscal e impositivo, en el sistema financiero y bancario y en las empresas estatales.

\subsection{Cambios en el sistema fiscal}

Como ya hemos visto, hasta mediados de los ochenta las empresas estatales transferían obligatoriamente todos sus beneficios en 
concepto de aportaciones directas al presupuesto del Estado, de manera que, hasta ese momento, no tenía mucho sentido hablar de política fiscal en China. Sin embargo, la reforma fiscal se hizo necesaria a medida que avanzaba la reforma, dado que las empresas estatales disponían de una mayor autonomía financiera, al tiempo que aparecían nuevas formas de propiedad en el sector privado, en el que el capital extranjero comenzaba a tener protagonismo.

De este modo, entre los años 1984 y 1985 se acometió la primera reforma fiscal importante, en la que se sustituyeron las transferencias directas por impuestos sobre los beneficios. En 1987, como se vio anteriormente, se completó esta medida con la introducción del sistema de responsabilidad por contratos. Ambas reformas se realizaron preservando siempre la propiedad estatal.

Sin embargo la realidad económica necesitaba un sistema fiscal a nivel nacional más moderno y desarrollado. Hasta ese momento, el sistema estaba excesivamente descentralizado y había muchas diferencias entre unas zonas y otras; además, había problemas de eficiencia impositiva. El gobierno central necesitaba fortalecer sus funciones macroeconómicas y reguladoras, y para ello necesitaba también establecer una fuente de ingresos adecuada y fiable (Naughton 2007).

Para hacer frente a las nuevas circunstancias, en 1994 las autoridades chinas iniciaron un nuevo programa de reforma fiscal que buscaba aumentar la capacidad recaudatoria del Estado. Es la primera legislación tributaria china orientada al mercado. Para ello se derogó previamente el sistema de responsabilidad por contratos y se procedió a simplificar y unificar las figuras impositivas a través de la creación de una nueva gama de impuestos. Además se incrementó la parte de los impuestos recaudada por el gobierno central y se diseñaron las reglas por las que se iban a repartir los ingresos entre él y los entes locales.

En los últimos años se han llevado a cabo nuevas reformas en el ámbito fiscal, como consecuencia de los compromisos adquiridos para la entrada en la OMC. Entre las más importantes destacan dos (OMC 2008a): en primer lugar la unificación del sistema del impuesto sobre la renta de las empresas con el fin de situar en condiciones de igualdad desde el punto de vista fiscal a las empresas con inversión extranjera y las empresas nacionales; y en segundo lugar, el inicio de proyectos piloto 
para transformar el actual IVA de impuesto sobre la producción en impuesto sobre el consumo?.

\subsection{Las empresas estatales}

En los años ochenta, como ya hemos apuntado, se habían introducido algunas reformas para orientar las empresas estatales al mercado. En los primeros años de la década de los noventa, la reforma de las empresas estatales continuó en ese camino y se centró en conseguir un aumento gradual de la autonomía empresarial (incrementando su independencia y haciéndoles responsables de sus pérdidas y ganancias), con el fin de fomentar su competitividad y eficiencia. En definitiva se trataba todavía de un proceso que podríamos denominar, en palabras de Bustelo (1996), de mercantilización sin privatización.

Aunque a comienzos de los noventa las empresas de propiedad estatal ya no tenían el mismo peso en la economía nacional que unos años antes, seguían en esta época representando un papel muy importante en la vida económica del país, fundamentalmente porque continuaban siendo la base de la industria pesada y de sectores claves y estratégicos, por el gran nivel de empleo que asumían y porque en aquel momento -en ausencia de un sistema de seguridad social estatal- eran las empresas estatales las que se ocupaban de suministrar servicios sociales a sus empleados. Por este motivo, y porque además muchas de ellas operaban con pérdidas, seguían siendo una de las cargas principales del Estado chino y uno de los temas pendientes de ser resueltos.

Con el objetivo de afrontarlo, a mediados de los noventa se puso en marcha un programa de privatización gradual de algunas de esas empresas. El gobierno chino comenzó a reducir significativamente las barreras que protegían contra la competencia a las empresas nacionales y a sus trabajadores, cambiando de manera importante la política aplicada al sector industrial estatal. En lugar de incentivar a las empresas estatales, como había hecho anteriormente, se hizo hincapié en la reestructuración. Se alentó a las empresas públicas a que se reorganizaran en compañías de

9 El IVA grava la venta o importación de mercancías y de algunos servicios, y es un impuesto basado en la producción, por lo que los bienes de capital están incluidos en la base tributaria (a diferencia de un IVA basado en el consumo). Por consiguiente, las actividades industriales en que se hace un uso intensivo del capital están penalizadas. 
accionariado común, aunque inicialmente, por lo general, el gobierno mantuviera la propiedad del $100 \%$ de las acciones (Naughton 2004). Así, en 1997, y por primera vez en China, la reforma de las empresas estatales se tomó como la pieza central de la siguiente etapa de reformas y Jiang Zemin (presidente de la República desde 1989 hasta 2003) anunció su determinación de reformar las más de cien mil empresas públicas del país (Perkins 1997).

El gobierno comenzó así un nuevo programa gradualista, pero esta vez de privatización, adoptando una forma peculiar que seguía el principio de "tomar las grandes, abandonar las pequeñas". Las grandes empresas estatales han seguido bajo la tutela y propiedad del gobierno central, mientras que las pequeñas y medianas se han dejado en manos de los gobiernos locales.

Así, ya consumada la entrada de China en la OMC, el gobierno continuaba con la intención de disponer de un grupo privilegiado de unas cincuenta empresas nacionales en sectores estratégicos. Aunque estas grandes empresas han sido parcialmente privatizadas -mediante su cotización en Bolsa - el Estado no ha perdido el control sobre las mismas. Asimismo, el gobierno ha fomentado con frecuencia fusiones entre estas empresas con el fin de hacerles ganar tamaño y mejorar la competitividad (Soler 2003).

Todas estas políticas han supuesto una transformación fundamental en la economía china. Hubo un efecto positivo inmediato sobre los ingresos fiscales, pero también hubo, y hay, cargas que soportar. El grupo que más perdió su posición "privilegiada" fue el de los trabajadores estatales (Naughton 2004). Algunos de ellos siguieron empleados en compañías de accionariado común, en las cuales el Estado era el accionista mayoritario, o en empresas totalmente privatizadas, pero millones de ellos fueron despedidos y el desempleo urbano se disparó a finales de los noventa.

Ésta es una de las razones más importantes a las que alude Naughton (2007) para distinguir las reformas de los ochenta y de los noventa. A las primeras las denomina reforma sin perdedores ${ }^{10}$, mientras que las segundas serían reformas con perdedores. A su juicio, a medida

10 Para un análisis detallado de esta cuestión véase Lau, Qian y Roland (2000). 
que China avanza en la transición el reparto de los beneficios de la misma es menos equitativo.

\subsection{El sector financiero}

Hasta 1979 el sector financiero de China, como en otras economías planificadas, tenía como función atender los planes de producción e inversiones del Gobierno. Dado que los medios de producción estaban en manos del Estado, no existían mercados de capitales, el Banco Popular de China (BPC) era prácticamente el único banco, y asumía la doble función de banco central y de banco comercial. Era la única institución tomadora de depósitos y la única entidad de crédito, y era la vía para canalizar los beneficios de las empresas estatales hacia otras empresas o hacia sectores prioritarios, lo cual se realizaba a través de un plan de crédito administrado y de conformidad con el Gobierno.

En la reforma financiera de 1984 se separaron sus funciones; el BPC siguió encargado de la política monetaria y de la regulación bancaria, mientras que para la realización de las labores propias de la banca comercial se crearon cuatro grandes bancos públicos, especializados en la concesión de créditos, cada uno de ellos en un área considerada clave para el desarrollo económico del país: el sector agrícola, el sector industrial, el comercio exterior y el sector de la construcción ${ }^{11}$. Estos asumieron la responsabilidad de aportar capital a las empresas de propiedad estatal.

En la segunda mitad de los ochenta el sistema bancario continuó diversificándose con la introducción de nuevos productos y la apertura de nuevos bancos comerciales; simultáneamente $-y$ lo que es más importante - se establecieron los primeros mercados de valores: Shanghai y Shenzhen. También comenzaron a surgir entidades financieras no bancarias, como intermediarios de mercados de valores o sociedades de gestión de valores.

A mediados de los noventa, cuando los cuatro grandes bancos públicos habían ido encauzando su actividad a la banca comercial, las autoridades chinas crearon tres nuevos bancos estatales especializados

11 El Banco Agrícola de China (vinculado a las zonas agrícolas y rurales), el Banco de China (especializado en transacciones internacionales), el Banco de la Construcción de China (especializado en la financiación de proyectos de construcción e infraestructura) y el Banco Industrial y Comercial de China (vinculado a los sectores industriales y comerciales en las zonas urbanas). 
con el fin de desempeñar funciones de política de préstamos para relevar a los Cuatro Grandes en esa función ${ }^{12}$. En esta época empezaron a surgir problemas de préstamos impagados, debido fundamentalmente a que se habían cargado al sistema bancario público grandes deudas contraídas por las empresas estatales.

En 1995 se promulgaron la Ley sobre el Banco Popular de China -que establecía el marco jurídico para el funcionamiento del BPCy la Ley sobre bancos comerciales - que regulaba la organización de la banca comercial-.

A finales de los noventa, después de la crisis asiática, comenzaron a ponerse en práctica una serie de mediadas aperturistas encaminadas a crear un sector competitivo y rentable. En aquel momento la participación extranjera era muy pequeña y aún muy restringida (por moneda, tipos de clientes o geográficamente). Para ello se redujo el intervencionismo estatal y el sector comenzó a abrirse gradualmente a la inversión y competencia exteriores. Además se mejoró la regulación y la supervisión bancaria y se produjo una reestructuración bancaria, que tenía como objetivo resolver el problema de los créditos fallidos, sobre todo de los Cuatro Grandes bancos. En 1999 se creó una compañía estatal de gestión de activos impagados para cada uno de ellos.

Como veremos más adelante, un elemento clave del proceso de liberalización financiera ha sido la adhesión de China a la OMC, según la cual China se comprometió a cumplir un calendario de apertura del sistema bancario a la competencia exterior (Liao 2006). Desde la adhesión, todos los bancos -incluso los extranjeros- han podido realizar ciertas transacciones en moneda extranjera, particularmente en lo que concierne a las actividades de depósito. Asimismo, desde 2003, los bancos extranjeros han sido autorizados a operar en el mercado mayorista en moneda local, pero con límites geográficos estrictos. También en 2003 se establecieron nuevas estructuras de regulación, entre ellas la Comisión de Reglamentación Bancaria de China (CBRC) $)^{13}$.

12 El Banco de Desarrollo de China, el Banco de Exportación e Importación de China y el Banco de Desarrollo de la Agricultura de China.

13 La CRBC es un organismo público de control y regulación que vela por el correcto funcionamiento y administración de todo el sistema bancario chino. Para ello tiene la capacidad de emitir normativas o de llevar a cabo controles e inspecciones. 
Desde 2004, inversores estratégicos extranjeros han adquirido acciones de cuatro de los cinco principales bancos comerciales de propiedad estatal. También han atraído inversores estratégicos extranjeros los bancos comerciales por acciones y los comerciales urbanos más pequeños.

El año 2006 marcó un hito en la continuación de la apertura del sector bancario, dado que se suprimieron las restricciones geográficas y las aplicadas a los clientes con respecto a las actividades comerciales en renminbis, así como otras restricciones no cautelares aplicadas a las operaciones de los bancos extranjeros. En septiembre de 2007 se permitió a seis bancos con financiación extranjera realizar actividades minoristas, y nueve bancos extranjeros estaban en proceso de convertir sucursales en filiales.

El proceso de reforma se ha centrado también en los últimos años en la mejora de la gestión empresarial. Recientemente se han establecido medidas sobre banca electrónica, para tratar de mejorar las normas en materia de gestión de riesgos y seguridad aplicables al sector.

En el Informe del gobierno presentado por China a la OMC ${ }^{14}$ para su último Examen de Políticas Comerciales, éste manifiesta que se ha logrado un avance decisivo en la reforma del sistema de valores de los bancos comerciales de propiedad estatal. En los últimos cuatro años, el Banco Industrial y Comercial de China, el Banco de China, el Banco de la Construcción de China y el Banco de Comunicaciones han completado sucesivamente la reforma de su sistema de acciones, y han salido a bolsa en los mercados de valores nacionales y/o extranjeros. Se han producido cambios profundos en la gestión empresarial y en el concepto de administración de estos bancos comerciales. El resultado ha sido una mayor consolidación general y una mejor calidad de activos y aptitudes de gestión.

No obstante, persisten vulnerabilidades importantes, y el sistema financiero de China es todavía incapaz de lograr plenamente su tarea central: la asignación de crédito de un modo eficiente a todos los sectores. Santabárbara (2007) apunta que se espera que el desarrollo económico, unido al proceso de reforma y liberalización de los mercados financieros, se traduzca en un aumento de la demanda de servicios financieros y en un mayor grado de sofisticación financiera.

14 Documento de la Organización Mundial de Comercio: WT/TPR/G7199, de 


\section{COMERCIO}

\section{LA ADHESIÓN DE CHINA A LA ORGANIZACIÓN MUNDIAL DE}

La transición hacia el mercado se ha acentuado desde diciembre de 2001, momento en el que China se adhirió a la $O M C^{15}$. Como consecuencia de ello ha tenido que asumir la normativa de esta organización, es decir, una serie de compromisos de apertura y liberalización de sus relaciones económicas con el exterior, que han dado lugar a nuevas reformas (además de las transformaciones previas que condicionaron la adhesión) ${ }^{16}$. Estos cambios han tenido $-y$ tendrán- consecuencias trascendentales para la economía china y para sus relaciones comerciales y de inversión con el resto del mundo.

\subsection{Situación previa e implicaciones formales generales}

A pesar del esfuerzo liberalizador que China había realizado previamente, antes de su adhesión a la OMC, aún perduraban en el país importantes obstáculos al comercio, en gran parte contrarios a las normas de dicha organización. Estos obstáculos pueden resumirse, como hace Soler (2003), en los siguientes puntos: dispersión arancelaria, falta de transparencia, restricciones cuantitativas, prohibición de distribuir libremente productos fabricados fuera de China en el interior del país, y escasa legislación sobre protección de la propiedad intelectual e industrial. Sin embargo, los productos chinos disfrutaban en la mayoría de los países de un acceso equitativo, análogo al del resto de países, es decir, en circunstancias similares a los procedentes de otros miembros de la OMC.

En este contexto, una de las consecuencias más inmediatas que se derivan de la entrada de China a la OMC es la inmediata aplicación de las obligaciones y principios generales que recogen sus Acuerdos. Entre ellos tienen especial relevancia los siguientes:

- Acuerdo GATT (Acuerdo General sobre Aranceles Aduaneros y Comercio), que abarca el comercio internacional de mercancías.

- Acuerdo GATS (Acuerdo General sobre el Comercio de Servicios).

15 Conviene precisar que Taiwán es Miembro de la OMC desde enero de 2002 (dado que su adhesión estaba vinculada a la adhesión previa de China), y Hong Kong y Macao (regiones administrativas especiales de China desde 1997 y 1999 respectivamente) desde enero de 1995.

WT/L/432).

16 Véase Protocolo de Adhesión de la República Popular China (documento 
- Acuerdo TRIPS (Acuerdo sobre Derechos de Propiedad Intelectual relacionados con el Comercio).

- Acuerdo TRIMS (Acuerdo sobre las Medidas en materia de Inversiones relacionadas con el Comercio).

No obstante, hay que tener en cuenta que el Protocolo de Adhesión no establecía el acceso pleno, inmediato y sin limitaciones de productos, servicios o proveedores extranjeros. En su lugar, el Estado chino se comprometió a eliminar gradualmente los obstáculos al comercio y ampliar el acceso a su mercado, pero estableciendo un calendario específico de liberalización para cada tipología de productos y servicios, que además no siempre culmina con la plena libertad de acceso.

Además de estos Acuerdos, el acceso supone la aceptación de la autoridad de la OMC para resolver conflictos; de este modo, China asume el sistema de solución de diferencias de la OMC, basado en los acuerdos y compromisos, y se somete a los Exámenes de las políticas comerciales, que para la Organización constituyen un ejercicio de transparencia.

\subsection{Relaciones comerciales}

Las relaciones comerciales de China desde su adhesión a la OMC se han visto afectadas, sobre todo, por las obligaciones derivadas del Acuerdo GATT. De acuerdo con Gertler (2004), los principios generales que asume China en esta materia pueden resumirse en los siguientes:

- Principio de no discriminación, que supone dar igual trato a todas las mercancías que entren en China, sin distinción en virtud de su origen. Adicionalmente, para China supone, entre otros compromisos concretos, eliminar el sistema dual de precios, reducir las restricciones al comercio e introducir acuerdos administrativos más uniformes.

- Principio de apertura del mercado, que implica la eliminación gradual de barreras de entrada al mercado chino: reducir los aranceles, eliminar las barreras no arancelarias, y abrir el sector servicios. Esta obligación está limitada por el calendario de compromisos específicos asumidos por China. 
- Transparencia y predecibilidad del comercio. China está obligada a publicar toda la regulación (leyes, reglamentos, etc.) relativa al comercio, tanto la que afecte a las reglas generales de la OMC, como la relativa a acuerdos específicos de ésta con China.

- Principio de comercio no distorsionado: afecta a asuntos como los subsidios, medidas antidumping o salvaguardas. China ha hecho fuertes compromisos en este terreno, incluyendo el de no utilizar subsidios a la exportación de bienes agrícolas.

El cumplimiento de estos compromisos ha liberalizado e incentivado las relaciones comerciales entre China y el resto del mundo. Actualmente, todas las empresas tienen derecho a importar y exportar todo tipo de mercancías y comerciar con ellas en todo el territorio aduanero, salvo unas pocas excepciones limitadas. Por otro lado, el grado de apertura comercial evoluciona en continuo aumento, llegando en 2007 al 63,3\%. La rebaja progresiva de aranceles que se inició en 2001 no se ha detenido desde entonces. Así, el arancel actual es resultado de las sucesivas rebajas decretadas desde el acceso y alcanza un nivel medio de $9,8 \%$ frente al nivel inicial del $15,3 \%$. Por grupos de productos, la media para productos agrícolas es del $15,2 \%$ y para productos industriales del $8,95 \%$. Desde el ingreso en la OMC, los aranceles no pueden ser incrementados por encima del nivel ya consolidado y fijado para cada uno de los productos. Asimismo, China ha consolidado todos los aranceles aplicados a las mercancías importadas (es decir, ya no puede aumentarlos sin compensar a las partes afectadas), algunos de ellos han sido eliminados, otros reducidos, y un tercer grupo podrá aplicarse hasta 2010 (OMC 2008a).

Por lo que respecta a los productos agrícolas, además de la reducción arancelaria, China aceptó limitar sus subvenciones a la producción agrícola y -como ya vimos- se comprometió a no aplicar subsidios a las exportaciones de estas mercancías. Sin embargo, se reservó el derecho de mantener un comercio de Estado exclusivo de algunos productos. En 2007 China mantuvo el comercio de Estado para un grupo reducido de productos, como por ejemplo los cereales, el azúcar y el petróleo.

En los productos industriales también se ha producido una importante reducción de la protección. Los sectores sometidos a un mayor ajuste han sido los de bebidas, tabaco y automóviles, dado que en ellos la protección está siendo especialmente reducida. Otras industrias con importantes reducciones serán textil, electrónica y las industrias ligeras. 
lanchovichina y Martin (2004) sostienen que la liberalización ayudará a mantener la eficiencia y la competitividad en estos sectores dado que muchos de ellos son intensivos en factor trabajo, donde China tiene ventaja comparativa. No obstante, la liberalización no está siendo tan significativa en lo que respecta a barreras no arancelarias.

A pesar de que se han producido grandes avances en el campo del desarme arancelario, siguen produciéndose conflictos. Recientemente, como consecuencia de los aranceles aplicables en el sector de la automoción, China ha perdido una disputa frente a Europa, Estados Unidos y Canadá. Por el contrario, debido al peligro que supuso China en algunos sectores (como el textil y la confección) al liberalizarse los intercambios, dio lugar a la adopción de actitudes proteccionistas en los últimos años en algunos países ${ }^{17}$.

Con todo ello, el saldo comercial de China en 2007 arrojó un superávit superior en un $47 \%$ al del año precedente ${ }^{18}$, las exportaciones en el periodo aumentaron un $25 \%$ y las importaciones se elevaron un $20 \%$, según datos de la OMC. En cuanto a su patrón de comercio, China tiene elevados déficit con los países asiáticos, y superávit con Europa y Estados Unidos, datos coherentes con su estrategia industrial que se basa en importar componentes de los primeros para su ensamblaje y reexportación a los segundos. Los destinos principales de la exportación de productos chinos en 2007 fueron: la Unión Europea, Estados Unidos, Hong Kong, Corea del Sur y Alemania. Las importaciones, por su parte, tuvieron como orígenes más importantes Japón, la Unión Europea, Corea del Sur, Taiwán, Estados Unidos y Alemania.

17 El textil y confección estuvieron regulados por acuerdos puntuales de carácter bilateral, y posteriormente, por el Acuerdo sobre los Textiles y el Vestido (ATV). Hasta 1995, los contingentes de productos textiles y de vestido se negociaban bilateralmente y se regían por las normas del Acuerdo Multifibras (AMF), que preveía la aplicación selectiva de restricciones cuantitativas cuando un brusco aumento de las importaciones de un determinado producto causara, o amenazara causar, un perjuicio grave a la rama de producción del país importador. El Acuerdo Multifibras constituía una importante desviación de las normas básicas del GATT. En enero de 1995 fue reemplazado por el Acuerdo sobre los Textiles y el Vestido de la OMC, que establecía un proceso de liberalización para incrementar progresivamente los contingentes existentes, hasta que se suprimieron finalmente en enero de 2005.

18 Se espera que el superávit continúe creciendo en 2008, reflejando el constante aumento de las reservas de divisas generado por los altos ingresos y la entrada de capital extranjero. Las reservas de divisas chinas, en continuo crecimiento, son las más elevadas del mundo. 


\subsection{Relaciones de inversión}

\subsubsection{Situación y marco legal previo}

\section{Regulación por actividad}

A lo largo de los años las inversiones extranjeras en China han recibido distinto tratamiento en función de la actividad de que se trate. La regulación en vigor cuando China ingresó en la OMC (el Catálogo para la Guía Industrial de la Inversión Extranjera ${ }^{19}$ ) databa de 1995 -con modificaciones de 1998- y agrupaba las inversiones extranjeras en cuatro grandes categorías: inversiones prohibidas, restringidas (cuya aprobación debe otorgarse por el gobierno central y donde la participación extranjera está limitada), incentivadas (las cuales gozan de un trato preferencial, tanto desde la perspectiva fiscal como en el proceso de autorización) y permitidas (plenamente abiertas a la inversión extranjera, sin límites a la misma, pero tampoco apoyadas especialmente con incentivos fiscales). Este último grupo se define por exclusión, estando permitidas todas aquellas inversiones que no hayan sido incluidas en cualquiera de las tres categorías anteriores.

Aunque las categorías se han mantenido hasta nuestros días, desde la adhesión a la OMC se han producido cambios en los requisitos de aprobación y en las actividades incluidas en cada una de ellas. La última modificación es de diciembre de 2007, cuando entró en vigor el nuevo Catálogo -que ha sustituido al anterior que databa de 2004-, y refleja la reorientación de la política económica global de China. Es decir, con este nuevo Catálogo China ha redefinido los sectores industriales que resultan favorecidos, restringidos y prohibidos para la inversión extranjera. Su objetivo principal es promover la inversión extranjera en industrias de tecnología punta, agricultura moderna y servicios. Por otro lado se deja de incentivar la inversión extranjera cuya finalidad sea la producción para la exportación, la industria manufacturera de gama baja y la industria altamente contaminante.

Por otro lado, antes de las últimas reformas, todos los proyectos de inversión en China debían someterse al examen y aprobación del Ministerio de Comercio o de sus delegaciones locales. Sin embargo hoy en día sólo requieren verificación por parte de las autoridades las

19 En la actualidad este documento es aprobado por el Ministerio de Comercio (MOFCOM) junto con la Comisión Nacional para la Reforma y el Desarrollo (NRDC). 
inversiones en proyectos "importantes o restringidos; todos los demás proyectos de inversión, independientemente de la cantidad invertida, sólo deben registrarse ante las autoridades competentes, como por ejemplo las comisiones locales de desarrollo y reforma (OMC 2008a).

\section{Fórmulas empresariales de inversión}

Históricamente las fórmulas empresariales con inversión extranjera ${ }^{20}$ más frecuentes en China han sido las empresas de capital mixto (joint ventures), las empresas de propiedad totalmente extranjera (wholly foreign owned enterprises, WFOE) y las oficinas de representación (Collado 2002). Las empresas conjuntas o de capital mixto pueden establecerse a través de dos fórmulas distintas: las empresas conjuntas de capital mixto (equity joint ventures) y las empresas conjuntas cooperativas (cooperative joint ventures). La diferencia fundamental entre ellas es que en las segundas los derechos y obligaciones tanto de los inversores extranjeros como de los nacionales están sujetos a un acuerdo contractual al que hayan llegado las partes, lo que les permite una mayor flexibilidad respecto a las primeras. Sin embargo, las empresas conjuntas de capital mixto han sido la fórmula más habitual utilizada para establecer una empresa conjunta probablemente porque su regulación era más detallada y se parecía más a las sociedades occidentales. Han sido la fórmula de inversión más adecuada para ciertos sectores, como por ejemplo la banca, que se encuentran en pleno proceso de liberalización.

Las empresas de capital totalmente extranjero (WFOE), que comenzaron a permitirse a finales de los ochenta, tienen una estructura similar a las sociedades limitadas habituales en otros países, de manera que resultan familiares a los inversores extranjeros. Inicialmente sólo eran permitidas en actividades orientadas a la exportación o que incorporaran tecnología avanzada, pero a partir de la incorporación de China a la OMC se están suprimiendo gradualmente estas condiciones, por lo que cada vez es más utilizada por los inversores extranjeros, debido la autonomía que implica. No obstante, como se verá más adelante, todavía existen sectores en los que la inversión 100\% extranjera está restringida e incluso

20 Para encontrar información de interés sobre la inversión extranjera en China, consúltese la página Web del MOFCOM a través del siguiente enlace: http://www.fdi.gov.cn/ pub/FDI_EN/default.htm. 
prohibida. Son industrias en proceso de liberalización, como los servicios financieros o la distribución. El ámbito de las WFOEs está en proceso de apertura, y seguirá liberalizándose, llegando probablemente a todos los sectores excepto los más sensibles políticamente, como el sector de la automoción.

Posteriormente se fueron estableciendo las oficinas de representación, cuya actividad es muy limitada. No son reconocidas como personas jurídicas con plenos derechos y sólo pueden dedicarse a las actividades empresariales que no generen beneficios directos; tampoco pueden firmar contratos comerciales, ni emitir facturas, ni llevar a cabo las actividades comerciales de almacenaje ni de distribución. Sin embargo, habitualmente son el primer paso que dan las empresas extranjeras al iniciar sus operaciones a gran escala en dicho país, y son la forma más utilizada para llevar a cabo actividades de investigación y seguimiento del mercado chino.

Cabe reseñar que algunas de las inversiones extranjeras surgían como consecuencia de los obstáculos existentes para la comercialización de productos extranjeros en el país, dado que hasta la entrada en la OMC estaba prohibido el establecimiento de redes de distribución comercial a empresas extranjeras (Collado 2002). El gobierno central autorizaba, bajo ciertas condiciones excepcionales y dentro de determinados planes piloto, algunas joint ventures de capital extranjero dedicadas a la distribución.

4.3.2. Implicaciones del ingreso en la OMC para las inversiones extranjeras

Los acuerdos de la OMC que afectan a las inversiones extranjeras en China y por tanto, aquellos que más cambios han motivado en la normativa reguladora de las mismas y en su progresiva liberalización son el Acuerdo General sobre el Comercio de Servicios (GATS) y el Acuerdo sobre Inversiones relacionadas con el Comercio (TRIMS).

En cumplimiento del acuerdo TRIMS se ha producido una reforma legislativa que ha ocasionado importantes cambios; quizás el más significativo sea la eliminación de determinados requisitos que China exigía a la inversión extranjera, como la obligación de exportar, la utilización de tecnología avanzada, el mantenimiento de un balance determinado en divisas y la obligación - para algunas empresas- de adquirir equipo, componentes y materias primas en China (Collado 2002). Este proceso ha 
supuesto la reforma de las leyes relativas a las distintas formas empresariales de $\operatorname{IDE}^{21}$ :

- La Ley de Empresas Mixtas (Joint Venture Law, 1979, reformada en 1990 y 2001) que distingue dos tipos de empresas mixtas:

- Las empresas mixtas por acciones o convencional (equity joint venture), regulada por la Ley de 15 de marzo de 2001 (Law of the People's Republic of China on Chinese-Foreign Equity Joint Ventures).

- La empresa mixta contractual o cooperativa (contractual o cooperative joint venture), regulada por la Ley de 31 de octubre de 2000 (Law of the People's Republic of China on Chinese-Foreign Contractual Joint Ventures).

- La Ley de Empresas de Capital Totalmente Extranjero (Law of the People's Republic of China on Enterprises Operating Exclusively with Foreign (apital), que fue publicada en 1986, si bien el Decreto que detalla su puesta en práctica no fue promulgado hasta 1990 (Detailed Rules for the Implementation of the Law of the People's Republic of China on Enterprises Operated Exclusively with Foreign (apital). La Ley fue nuevamente reformada el 31 de octubre de 2000 y las nuevas reglas de implantación fueron aprobadas en abril de 2001.

Además, desde $2004^{22}$ se permite el establecimiento de dos tipos de empresas comerciales:

- Las empresas extranjeras de distribución o empresas comerciales de capital extranjero (Foreign Invested Commercial Enterprises, FICE), que son empresas de distribución mayorista y minorista dentro de China que no desarrollan actividades de comercio exterior.

- Las empresas de comercio exterior, o compañías de trading, dedicadas a actividades de importación/exportación de mercancías de fabricación propia o ajena, de o hacia China.

\footnotetext{
21 Consúltese la Guía País 2008 elaborada por la Oficina Económica y Comercial de España en Pekín.

22 En virtud de la publicación de las Medidas para la Administración de la Inversión Extranjera en el Sector Comercial, publicadas por el MOFCOM el 16 de abril de 2004.
} 
Asimismo, la entrada en la OMC está suponiendo la lenta, pero progresiva, apertura de un gran número de sectores claves de la economía china. Los compromisos asumidos por China en materia de comercio de servicios (GATS) ${ }^{23}$ afectan a un número de sectores cuyo acceso a la inversión extranjera estaba hasta el momento de la adhesión prohibido o muy restringido. De ellos se derivan la apertura de la inversión extranjera a actividades como la banca, los seguros, la distribución comercial y las telecomunicaciones. En la mayor parte de los sectores la liberalización se está llevando a cabo de forma progresiva, tanto en el ámbito geográfico como en los porcentajes de participación extranjera permitidos, cumpliendo el calendario de liberalización previamente acordado. De todos modos, este proceso está todavía inacabado; de hecho, el desarrollo del sector de los servicios figura como prioridad en el Undécimo Plan Quinquenal para el Desarrollo Económico y Social Nacional $^{24}$. En él se expone como propósito que China siga abriendo el sector servicios y eliminando barreras gradualmente a los inversores extranjeros - aunque como ya se ha expuesto, en algunos sectores todavía no se permite la participación de las empresas de capital totalmente extranjero (WFOE) - y en las empresas mixtas (la parte china deberá mantener el control principal por ejemplo los sectores bancarios y de seguros). No obstante, es preciso recalcar que los compromisos asumidos por China con la OMC respecto del sector servicios son muy amplios. En opinión de Mattoo (2004) han representado la reforma más radical de este tipo en la historia de la OMC, aunque están sujetos a reservas o a salvedades más frecuentes que en el caso de otros países.

Al igual que ha ocurrido con las relaciones comerciales, la presencia de China en los flujos de inversión directa mundiales, sobre todo como receptor de la misma, ha aumentado notablemente desde el inicio de la reforma, convirtiéndose en los últimos años en uno de sus grandes receptores mundiales. La IDE que recibe China se dirige en buena parte a sectores orientados a la exportación, y su importancia para la economía china puede evaluarse atendiendo al alto porcentaje del PIB que ocupa, alrededor del 20 por ciento en 2006; por todo ello la IDE ha

23 Estos compromisos están recogidos en el Proyecto de Informe del Grupo de Trabajo sobre la adhesión de la República Popular China: Lista de compromisos específicos en materia de servicios. Documento: WT/ACC/CHN/49/Add.2.

24 Las líneas generales pueden verse en la información en línea de la Comisión Nacional de Desarrollo y Reforma (NDRC): http://en.ndrc.gov.cn/hot/t20060529_71334.htm. 
sido una gran fuente de empleo para el país, alcanzando además cotas de productividad sustancialmente mejores que la media nacional, ya que la productividad de los empleados en las empresas con inversión extranjera radicadas en China es más de nueve veces mayor que la del resto de la economía (según datos de la OMC).

Sin embargo, su papel como inversor en el exterior es todavía poco importante, aunque las salidas de inversión extranjera directa de China han experimentado un extraordinario aumento en los últimos años; este incremento se ha debido en buena parte a los esfuerzos de China por asegurarse el suministro de recursos naturales y combustibles con el fin de poder mantener su ritmo de crecimiento.

De cara al futuro más inmediato, los objetivos de las autoridades en materia de IDE se plasman en el Undécimo Plan Quinquenal Chino (2006-2010) para la utilización de la Inversión Extranjera ${ }^{25}$ que recoge, entre otras cuestiones, la política de China para la utilización de la inversión extranjera en este periodo, así como los principales retos en este ámbito; entre estos últimos podemos destacar los siguientes:

- Orientar a los inversores extranjeros hacia una optimización y una mejora de la estructura industrial En concreto, en este periodo se quiere fomentar la IDE hacia la agricultura moderna, la industria tradicional china, la automoción, la electrónica y las tecnologías de la información, entre otros.

- Reforzar las normativas de ahorro de energía y de respeto al medio ambiente. Para ello se pretende prohibir las inversiones extranjeras en proyectos de bajo contenido tecnológico, de gran consumo de recursos o altamente contaminantes, así como fomentar los proyectos de protección del medio ambiente y los relacionados con fuentes de energía limpias y respetuosas con el mismo.

- Continuar la apertura gradual de la industria de servicios por medio de una inversión extranjera equilibrada. Siguiendo los compromisos con la OMC, China dará prioridad a la entrada de las compañías de seguro extranjeras y a instituciones especializadas en operaciones de pensiones, en servicios médicos y en seguros agrarios. En el sector bancario, la apertura seguirá caracterizada

25 Este documento fue publicado por la NDRC en su página Web el 9 de noviembre de 2006, como parte integrante de la totalidad del undécimo plan quinquenal. Puede consultarse un resumen del mismo en www.InterChinaConsulting.com. 
por una gestión prudente y de control del riesgo, con una división práctica de los bancos nacionales y extranjeros que operan en China. Se pretende fomentar la asociación estratégica entre los bancos locales y extranjeros, siempre manteniendo el control en manos chinas. También habrá una apertura gradual a la inversión en otros sectores tales como el de seguridad, telecomunicaciones, minorista, logística, turismo y entretenimiento, todo ello según los compromisos de China con la OMC.

- Promocionar un desarrollo económico equilibrado en las distintas regiones.

- Creación de un entorno de inversión más imparcial y favorable para los inversores extranjeros. Este reto se ha conseguido en gran medida gracias a la entrada en vigor en enero de 2008 de la "Ley del impuesto sobre la renta de las sociedades" 26 , que alteró la estructura de los incentivos fiscales otorgados a las empresas con inversión extranjera. Hasta finales de 2007 China otorgaba en sus políticas impositivas un trato más favorable a las empresas con inversión extranjera que a las nacionales. Sin embargo, la aplicación de esta nueva Ley ha puesto fin a la coexistencia de dos sistemas tributarios aplicables por separado, ha reducido el tipo legal del impuesto sobre la renta del 33 al 25 por ciento (con algunas excepciones), ha unificado los métodos y las normas para las deducciones antes del pago de impuestos, y ha consolidado los incentivos de la política impositiva.

\subsection{Propiedad intelectual}

Además de lo anterior, como ya se ha señalado, la adhesión a la OMC obliga a China a cumplir íntegramente el acuerdo TRIPS (Acuerdo sobre Derechos de Propiedad Intelectual relacionados con el Comercio) y, con él, a crear un marco legal en materia de protección de la propiedad intelectual que se ajuste a los patrones internacionales ${ }^{27}$. Esto supone significativos avances en el campo jurídico y judicial, como la creación de

\footnotetext{
26 Se puede consular en: http://www.fdi.gov.cn/pub/FDI_EN/Laws/law_en_ info.jsp?docid $=76240$.

27 Para ver un análisis profundo y una valoración del régimen de derechos de propiedad intelectual en China, consúltese Maskus (2004).
} 
algunas leyes y la modificación de otras entre las que podríamos destacar la "Ley de Patentes", la "Ley de Marcas", y la "Ley de Derechos de Autor (todas ellas modificadas en 2001), o la "Ley Anti-competencia Desleal" (modificada en 2007). Además, China es miembro de la Organización Mundial de la Propiedad Intelectual $(\mathrm{OMPI})^{28}$ y ha firmado diversos acuerdos multilaterales relacionados con esta materia. El Gobierno chino es cada vez más consciente de la importancia de proteger los derechos de propiedad intelectual; sin embargo, y a pesar de reconocer los avances en este campo, la OMC manifiesta su preocupación acerca del cumplimiento de China de sus obligaciones a este respecto ${ }^{29}$.

\section{CONCLUSIONES}

En este trabajo hemos intentado analizar ordenadamente los aspectos más relevantes de la reforma económica china, así como los rasgos más significativos de sus consecuencias. Como hemos visto, a lo largo de los últimos treinta años la economía china y el papel que ésta desempeña en la economía mundial se han transformado drásticamente. En concreto, China se ha convertido en una economía mixta y abierta, cuando comenzó siendo una economía totalmente planificada y cerrada a exterior. Desde que puso en marcha el proceso de reforma económica a finales de la década de los setenta su economía ha sufrido una de las evoluciones más exitosas y más significativas de la historia reciente que, dada su magnitud en términos de extensión geográfica y población, le ha convertido en un actor económico mundial de primer orden. Hoy nadie duda de la importancia económica de China.

Sin embargo, aún tiene ante sí importantes retos por afrontar, entre ellos, continuar reformando las instituciones y la legislación para adaptarlas a la realidad económica que vive el país. Además, entre otras medidas concretas, debe aumentar el consumo interno, reducir la desigualdad de ingresos entre las zonas rurales y urbanas, aumentar el gasto en investigación y desarrollo, mejorar la protección intelectual, aumentar el gasto público en servicios sociales (como sanidad, educación,

28 Organismo especializado de la ONU cuyo fin es preservar y aumentar el respeto hacia la propiedad intelectual en todo el mundo y fomentar el desarrollo industrial y cultural, así como estimular la actividad creadora y la transferencia de tecnología.

29 Documento WT/TPR/S/199 de abril de2008 de la OMC. 
pensiones, etc.) para velar por el bienestar de una sociedad de mil trescientos millones de habitantes e incrementar, intensificar y mejorar las políticas medioambientales, intentando corregir el desequilibrio existente entre la expansión económica y la degradación medioambiental que sufre el país.

\section{BIBLIOGRAFÍA}

BHATTASALI, D.; S. LI and W. MARTIN (eds.) (2004) China and the WTO. Washington, DC.: The World the Bank; Oxford University Press.

Bustelo, P. (1996) "Progreso sin privatización en China: la reforma de las empresas estatales en los años noventa", Revista de Estudios Asiáticos, 3, pp. 117-127.

- y Y. FERnÁNDEZ LOMMEN (1996) La economía china hacia el siglo XXI. Veinte años de reforma. Madrid: Editorial Síntesis.

CHANG, H.J. and P. NolAN (eds.) (1995) "Europe versus Asia: Contrasting Paths to the Reform of Centrally Planned Systems of Political Economy", The transformation of the Communist Economies: Against the Mainstream. New York: St. Martin's Press, pp. 3-45.

CollADO, A. (2002) "La inversión directa en China: implicaciones derivadas de su entrada en la OMC", Información Comercial Española, Revista de Economía, 797, pp. 77-91.

Fanjul, E. (1994) Revolución en la revolución. China, del maoísmo a la era de la reforma. Madrid: Alianza Editorial.

- (1996) "¿Es China un peligro para el mundo?", Revista de Estudios Asiáticos, 3, pp. 81-92.

FUnG, H.G.; C. PEl and K.H. ZHANG (eds.) (2006) China and the Challenge of Economic Globalization: The Impact of WTO Membership. New York: M.E. Sharpe.

GE, W. (1999) "Special Economic Zones and the Opening of the Chinese Economy: Some Lessons for Economic Liberation", World Development, 27, No. 7, pp. 1267-1285.

GerTLER, J.L. (2004) "What China's WTO accession is all about". D. BHATTASALI, S. LI and W. MARTIN (eds.) China and the WTO. Washington, DC.: The World the Bank; Oxford University Press, pp. 21-28. 
Groves, T.; Y. Hong, J. MCMilLAN and B. NAUGHTON (1994) "Autonomy and Incentives in Chinese State Enterprises", Quarterly Journal of Economics, 109, No. 1, pp. 183-209.

HuANG, J.; K. OTSUKA and S. Rozelle (2004) "The Role of Agriculture in China's Development" [http://www.economics.utoronto.ca/brandt/th ematic-paper.htm].

IANCHOVICHINA, E. and W. MARTIN (2004) "Economic Impact of China's Accession to the WTO". D. BHATTASALI, S. LI and W. MARTIN (eds.) China and the WTO. Washington, DC.: The World the Bank; Oxford University Press, pp. 211-236.

INTERCHINA CONSULTING [www.InterChinaConsulting.com].

JefFerson, G.H. and T.G. RAWSKI (1994) "Enterprise Reform in Chinese Industry", Journal of Economic Perspectives, 8, No. 2, pp. 47-70.

LAU, L.J.; Y. QIAN y G. ROLAND (2000) "Reform without Losers: An Interpretation of China's Dual-Track Approach to Transition", Journal of Political Economy, 108, No. 1, pp. 120-143.

LIAO, M. (2006) "Institutional Reform in the Chinese Banking System and China's Implementation of Commitments to the WTO". H.G. FUNG, C. PEl and K.H. ZHANG (eds.) China and the Challenge of Economic Globalization: The Impact of WTO Membership. New York: M.E. Sharpe, pp. 207-234.

MASKUS, K.E. (2004) "Intellectual Property Rights in the WTO Accession Package". D. BhATTASALI, S. LI y W. MARTIN (eds.) China and the WTO. Washington, DC.: The World the Bank; Oxford University Press, pp. 4968.

MATTO, A. (2004) "The Services Dimension of China's Accession to the WTO". D. BHATTASALI, S. LI y W. MARTIN (eds.) China and the WTO. Washington, DC.: The World the Bank; Oxford University Press, pp. 117-140.

MinISTRY OF COMMERCE OF PEOPLE'S REPUBLIC OF CHINA (MOFCOM) [http://engl ish.mofcom.gov.cn; http://www.fdi.gov.cn/pub/FDI_EN/default.htm; http://www.fdi.gov.cn/pub/FDI_EN/Laws/law_en_info.jsp?docid=76240].

NAUGHTON, B. (2004) "La transformación de China", Economía Exterior, No. 30, pp. 120-143.

- (2007) The Chinese Economy: Transitions and Growth. Cambridge, MA: The MIT Press.

NATIONAL DEVELOPMENT AND REFORM COMmission [http://en.ndrc.gov.cn/].

Nolan, P. (1994) "The China Puzzle: Touching Stones to Cross the River", Challenge, January-February, pp. 25-31. 
Oficina EConómica y Comercial de España en Pekín. Guía país. China 2008 [http: / / www.oficinascomerciales.es/icex/cda/controller/pageOfecom es/0,5310,5280449_5296122_5287111_4131344_CN,00.html].

Organización Mundial De COMERCIO. Protocolo de Adhesión de la República Popular China. WT/L/432, de 23 de noviembre de 2001; Documento WT/ACC/CHN/49/Add.2; Documentos WT/TPR/S/199 y WT/TPR/G/199 [http://www.wto.org].

PerkINS, D.H. (1994) "Completing China's Move to the Market", The Journal of Economic Perspectives, 8, No. 2, pp. 23-46.

- (1997) "Have China's Economic Reforms Stalled?", Development Discussion Paper, No. 613. Harvard Institute for International Development.

SANTABÁRBARA, D. (2007) "El proceso de apertura el sector bancario chino y el papel de la banca extranjera. Situación y perspectivas", Estabilidad Financiera, 13, pp. 103-122.

SINGH, A. (1996) "El Plan, el mercado y la transición gradual en China", Revista de Estudios Asiáticos, 3, pp. 55-80.

SOLER, J. (2003) El despertar de la nueva China. Madrid: Editorial Catarata. 